\title{
Urban regeneration policies and mental health in a context of economic crisis in Andalusia (Spain)
}

\author{
Ángel R. Zapata Moya ${ }^{1}$ (D) Clemente J. Navarro Yáñez ${ }^{2}$
}

Received: 21 February 2019 / Accepted: 1 August 2020 / Published online: 19 August 2020

(c) Springer Nature B.V. 2020

\begin{abstract}
Literature suggests that urban regeneration policies might contribute towards improving mental health of residents, but to date there is a lack of empirical research on how these policies and downward social mobility can interact and influence health outcomes. The current study aims to explicitly test whether regeneration policies implemented in deprived Andalusian urban places (southern Spain) moderate the use of anxiolytics and/or antidepressants, taking into consideration families' downward social mobility during the recent period of economic crisis in Spain. We designed a post intervention survey to retrospectively compare the evolution of psychotropic drug consumption in target and comparison areas. We observe a general increase in the use of anxiolytics and/or antidepressants from 2008 to 2015, specifically for people in whose families the economic crisis had the greatest impact (odds ratio $=2.18$; $p$ value $<0.001$ ). However, better evolution is observed among residents of the target areas compared with residents of similar urban areas where this kind of polices have been not in force (odds ratio $=0.50 ; p$ value $<0.05$ ). Therefore, urban regeneration policies might act as moderators of the risk of mental health, particularly when people are subject to the loss of individual/family resources in urban vulnerable contexts.
\end{abstract}

Keywords Urban renewal $\cdot$ Housing policies $\cdot$ Economic crisis $\cdot$ Mental health $\cdot$ Health inequality

Electronic supplementary material The online version of this article (https://doi.org/10.1007/s1090 1-020-09774-0) contains supplementary material, which is available to authorized users.

Ángel R. Zapata Moya

arzapmoy@upo.es

1 Department of Social Anthropology, Basic Psychology and Public Health, The Urban Governance

Lab (CSPL-UPO), Universidad Pablo de Olavide, Ctra. de Utrera, km. 141013 , Building 11,

Office 3-05, Seville, Spain

2 Department of Sociology, The Urban Governance Lab (CSPL-UPO), Universidad Pablo de Olavide, Ctra. de Utrera, km. 1 41013, Building 11, Office 4-22, Seville, Spain 


\section{Introduction}

A wide range of studies have documented that mental health systematically varies according to the characteristics of place and neighbourhoods (Driessen et al. 1998; Ross 2000; Weich et al. 2002; Silver et al. 2002; Fone and Dunstan 2006; Cagney et al. 2014). Current research priorities in this field signal the need to improve causal inference in relation to the way certain stressful elements, specific social processes and institutional interventions at the community level can influence the probability of suffering health problems and can shape health inequality in urban areas (Diez Roux and Mair 2010; Evans 2003; Thomson et al. 2006).

Literature suggests that urban policies might contribute towards mitigating health inequality through different pathways, for example: (1) enhancing access to certain material and non-material resources in deprived communities; (2) directly improving neighbourhoods' physical and social environment by ensuring the fairer distribution of community factors that can promote health, or transforming those which can be harmful; and (3) improving opportunities for active participation, increasing social capital and empowering communities (Northridge and Freeman 2011; Kawachi and Berkman 2014; Baba et al. 2017; Northridge et al. 2003).

Area based policies might be conceived of as institutional interventions aimed at improving the resources of residents and communities where social problems are highly concentrated. This type of initiatives can be conceived as 'natural experiments' through which we can assess whether a range of institutional interventions have any effects on residents' wellbeing (Baba et al. 2014; Mehdipanah et al. 2018). In this regard, externalities can sometimes disrupt the intended objectives of interventions and might obscure their potential benefits on population health. Some scholars have suggested the recent economic crisis is a major disruptive factor with regard to assessing the impact of urban regeneration programmes implemented during the crisis period (Jongeneel-Grimen et al. 2016). However, externalities also provide a unique opportunity to test whether area-based interventions can moderate its negative influence on health, specifically when individual resources strongly decrease. In other words, the economic crisis can also be conceived as 'natural experiment' that modifies the exposure of individuals to economic turmoil. As far as we know, to date there is a lack of empirical research that tries to explicitly explore how urban regeneration policies and downward social mobility can interact and influence health outcomes. In this vein, some studies have suggested that during the economic crisis, urban regeneration policies seem to have been able to safeguard the residents from detrimental developments of health (Droomers et al. 2016; Mehdipanah et al. 2014).

Using psychotropic drug use as an indicator of mental health disorders (Barceló et al. 2016; Malard et al. 2017; Silva et al. 2017; Martin-Carrasco et al. 2016), the objectives of this study are: (1) to investigate whether the probability of consumption of anxiolytics and/or antidepressants has increased in the both periods studied (before and after the economic crisis). (2) to explore the association between the loss of resources in the household, as an indicator related to downward social mobility, and such consumption. (3) Finally, we explicitly test whether urban regeneration policies in deprived urban areas moderate the consumption of anxiolytics and/or antidepressant considering the evolution of families' socioeconomic conditions during the crisis period. Our main hypothesis is that urban regeneration policies may act as a buffer for mental health problems, especially for more vulnerable people that have suffered negative impacts on their socioeconomic positions during the crisis period. 


\section{Methods}

\subsection{Population, policies and data}

In the present study we analyse the potential impacts of two area-based programmes: the first one is 'Urban Rehabilitation Areas' (ARB), which was launched from 2000 to 2012 by the Regional Government of Andalusia. The ARB initiative policy framework aims at improvement of the built environment and habitability and provides social support to families and communities in re-built houses and buildings. The second programme is 'Areas in need of Social Transformation' (ZNTS), It was launched in 2001 and is still running. It is an annual programme that encompasses and promotes social integration initiatives on urban places whose populations suffer from structural poverty, housing and urban deterioration, lack of infrastructure, equipment and public services, high rates of absenteeism and school failure, high unemployment rates, serious training deficiencies and significant hygienic sanitary deficiencies. Although the ZNTS program only targets deprived urban areas, both initiatives overlap each other in more than 60 per cent of the intervened areas selected for this study.

A post-intervention survey was designed including a health module in selected areas of large Andalusian cities ( $\geq 100,000$ inhabitants). Specifically, urban areas where ARB initiative has been running the longest and actions have been particularly intensive up to 2012. The survey also was conducted in comparison areas of the same cities which have been not intervened over the same period and have similar characteristics that target areas (within the same quintile of the municipal urban inequality, having a population size that differs from target area by no more than 50 per cent, and having a similar types of buildings and urban fabric).

Respondents were selected using multi-stage sampling: primary units contain 17 target and 16 comparison areas. Secondary units were 97 census tracts selected within each urban area. Lastly, individuals ( $\geq 18$ years old) were selected using a system of random routes within census tracts, with quotas by gender and age $(\mathrm{N}=5679)$. The data was gathered between 26 December 2014 and 21 March 2015, through face-to-face interviews. Given that economic crisis effects have been stronger in socioeconomic vulnerable areas (see supplementary data: vulnerable area information), we decided to restrict our sample to those respondents living in the 73 census tracts classified as vulnerable urban areas according the 2001 Spanish Urban Vulnerability Atlas (Ministerio de Fomento 2015). Moreover, to consider potential residential mobility derived from interventions, we used information only from interviewees who stated they had lived in the area for 10 or more years and who were within the 30-65 age range $(\mathrm{N}=1651)$.

\subsection{Measurements}

\subsubsection{Psychotropic drug consumption}

To assess the potential effects of area-based interventions while taking into consideration the mental health status at a previous period as well as post-intervention, we include questions on the consumption of anxiolytics and/or antidepressants during some period before 2008 and a second question on consumption of anxiolytics and/or antidepressant during the last two weeks prior to the interview. This allowed for the design of a dependent variable 
that provides information about the psychotropic drug use for each interviewed person at two different periods (coded as $1=$ yes; $0=$ no).

\subsubsection{Independent variables}

Our variables of interest are, first, subjects' exposure to area-based interventions (coded as $1=$ Target areas; $0=$ comparison areas). Second, we are interested in finding out whether area-based interventions mitigate the potential negative effect of downward social mobility on the risk of mental health disorders. In this case, we combine the following information to measure this phenomenon: First, we include questions that are intended to capture whether the household faced the enforced inability to pay eight basic expenses during the last 12 months (period 1), and whether they had faced any ten years previously (period 0). Using this information, we built an indicator for both periods that ranges from 0 to 8 , with higher values indicating a greater level of household deprivation. Second, we also consider questions on self-assessment of family' socioeconomic status (SES) at the interview (period 1) and ten year ago (period 0). To capture the negative impact of the economic crisis, we computed the differences between period 0 and period 1 in self-reported family' SES and household deprivation indicator. After both indicators were standardized, we performed a Principal Component Analysis, which resulted in one extracted factor that summarizes the 75 per cent of total variance (see supplementary material: PCA crisis impact variables). Lastly, we used the factorial scores from the extracted factor as our independent variable. It ranges from -3.98 to 4.95 , with the highest values representing the greatest negative impact of the economic crisis on families' SES. Analyses were adjusted for the following variables: gender (reference category: male), education level (reference category: higher education), age in years and family's SES at observation level.

\subsubsection{Reliability of retrospective measures}

Retrospective readings can be misleading due to recall bias. Nevertheless, although the reliability and validity of these questions can gradually decrease over time in the case of antidepressant use (Boudreau et al. 2004), some studies have shown that it is possible to assess antidepressant treatment history through interviews and retrospective questions (Posternak and Zimmerman 2003; Posternak et al. 2004). Indeed, other researchers have confirmed that there is no difference in retrospective assessment sensitivity between cases and controls (Cotterchio et al. 1999 2000). Aware of the fact that underestimation of the level of consumption of these drugs can occur with these types of questions; our main concern was to check whether, if that was the case, there were any differences between the target and comparison areas. The prevalence of anxiolytic and/or antidepressant consumption in our retrospective question does not vary significantly ( $p$ value $=0.269$ from $\chi 2$ test $)$ across target and comparison areas, 12.4 per cent (IC 95\%: 10.4-14.5) and 10.6 per cent (IC 95\%: 8.2-13) respectively. Furthermore, we tried to externally validate our retrospective indicator using the information provided by the 2006 Spanish National Health Survey (SNHS). First, according to the SNHS, the prevalence of antidepressant uses among people aged 30-65 and living in vulnerable census tract from Andalusia was 8.3 per cent (IC 95\%: 6-10.5) and for the estimation through our retrospective question it was 7.6 per cent (IC 95\%: 6.4-9). Second, the prevalence in the consumption of anxiolytics was 10.4 per cent (IC 95\%: 8-13) and 10.5 per cent (IC 95\%: 9.1-12.1) respectively. Based on this external comparison, we assume the reliability of our retrospective assessment. 


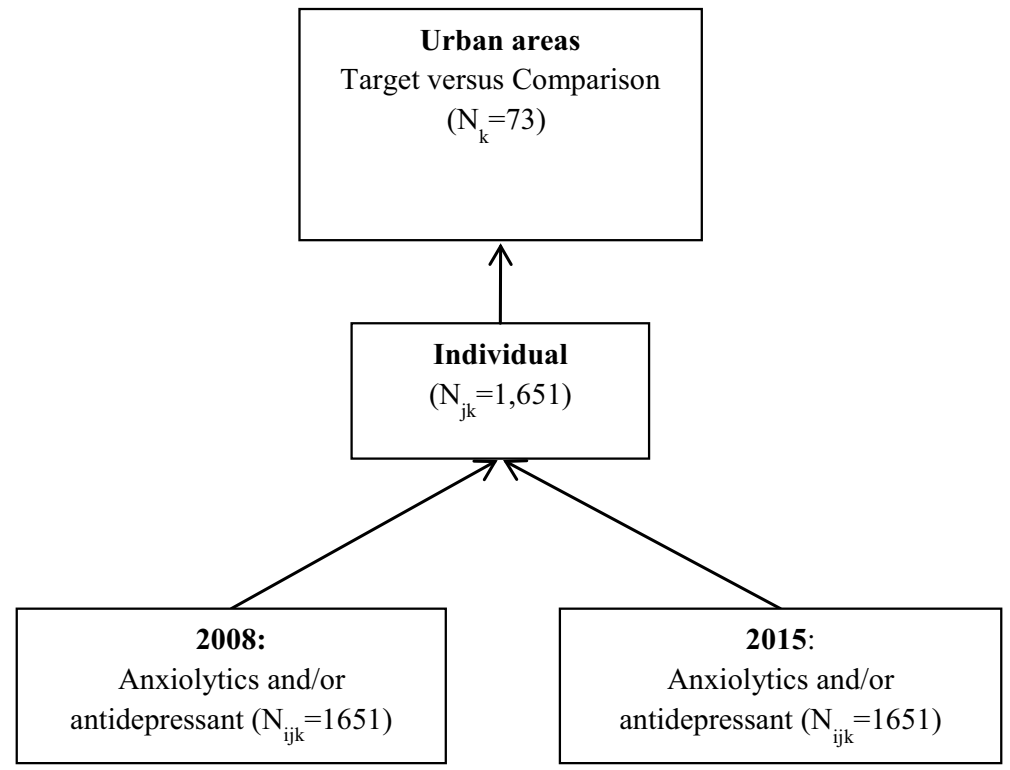

Fig. 1 Hierarchical structure with two repeated measurements

In addition, as we use retrospective questioning about family SES before the crisis period, to test if potential recall bias in the retrospective questioning may affect the differences between target and control areas, we previously compared the means of the negative impact of the economic crisis on families' SES among target and control areas using the ANOVA test. This analysis shows the means of the economic crisis impact on family' SES were not statistically different for respondents in target and control areas (See supplementary material: $\mathrm{F}=2.69, p$ value $>0.10$ ).

\subsection{Analysis}

The survey design and the use of both retrospective questions and referring to the time of the interview provides us with a data structure including two observations on psychotropic drug consumption for each interviewee at the beginning and at the end of the intervention $\left(\mathrm{N}_{\mathrm{ijk}}=3302\right)$ grouped at the individual level $\left(\mathrm{N}_{\mathrm{jk}}=1,651\right)$ and nested in urban areas $\left(\mathrm{N}_{\mathrm{k}}=73\right)$. This results in a hierarchical structure with two repeated measurements in time (see Fig. 1).

Therefore, we estimated multilevel logistic models with repeated measurements in the following steps: Firstly, we computed a null model including only the intercept to explore the variance distribution across periods, individuals and urban areas (See complete models in supplementary material). Secondly, we included all variables at the individual level and observation period in the next model, the objective being to explore whether a period effect on psychotropic consumption could be confirmed (2008 vs. 2015). Thirdly, we included an interaction term for the impact of economic crisis on family SES and the period variable to confirm whether any potential increase in psychotropic consumption could be attributed to the negative consequences of the economic crisis. Lastly, we computed a complete 
model including interaction terms for intervention and period, and intervention and the impact of economic crisis on family SES. The objective here was to verify whether areabased interventions moderate the potential crisis effect on anxiolytic and/or antidepressant consumption.

The analyses were carried out using the MLwiN software package (version 2.32). We used the Markov Chain Monte Carlo (MCMC) method, available in this package. This method seems to offer better bias control and more conservative hypothesis test compared with maximum likelihood estimates, specifically when cross-level interactions are being considered (Stegmueller 2013).

\section{Results}

The prevalence of anxiolytic and/or antidepressant consumption appears to have increased from 2008 and 2015. At the same time, self-reported family SES decreased after the economic crisis in both types of areas. However, the increase of psychotropic drug consumption is only statistically significant for residents in the comparison areas (an increase of approximately $4.5 \%$; $p$ value $=0.018$ from $\chi^{2}$ test) and and there is no evidence of this increase in target areas as the $p$ value is higher than 0.10 . (approximately $1.1 \% ; p$ value $=0.469$ from $\chi^{2}$ test) $($ Table 1$)$.

Table 2 presents the multilevel logistic analyses with repeated measurements. The findings from model 1 confirm the existence of a period effect. Specifically, the likelihood to consume psychotropic drugs increased in 2015 compared with 2008 (Odds Ratio $=1.51$; $p$ value $<0.05)$. Moreover, it can also be observed that a higher family SES decreases the likelihood of consumption (Odds Ratio $=0.83$; $p$ value $<0.01$ ). Model 2 adds the interaction terms between the crisis's impact on family SES and period. Specifically, our findings signal that people who suffered more from the consequences of economic crisis seem to have an increased probability of consumption in 2015 compared with 2008 (Odds Ratio $=2.18 ; p$ value $<0.001$ ). In addition, by including this interaction term, the period effect indicated as result of the previous model ceases to be statistically significant, which indicates that the period effect might be partly explained by the impact of the economic crisis on family SES.

The findings from model 3 suggest that area-based interventions moderate the period effect and the crisis impact on the likelihood of psychotropic drug consumption. The first moderation effect can be appreciated by considering the cross-level interaction term among the intervention (target areas) and period (2015 vs. 2008). This indicates a better evolution of the likelihood of consumption among residents of the target areas than for residents of the comparison ones (Odds Ratio $=0.40 ; p$ value $<0.01$ ). Second, the result of the interaction between the exposure to interventions and the impact of economic crisis suggests that area-based initiatives reduced the likelihood of consumption among people who suffered more strongly from the negative consequences of the economic crisis (Odds Ratio $=0.50$; $p$ value $<0.05)$. Model predictions also shows that trends in the use of anxiolytics and/or antidepressants from 2008 to 2015 have increase, specifically for people in whose families the economic crisis had the greatest impact. However, this trend is notably attenuated for residents in target compared with resident in control areas (Fig. 2). 
Table 1 Descriptive statistics

\begin{tabular}{|c|c|c|c|c|c|}
\hline \multirow[b]{2}{*}{ Variables at observation periods } & \multicolumn{2}{|c|}{ Control areas $(\mathrm{N}=29)$} & \multicolumn{2}{|c|}{ Target areas $(\mathrm{N}=44)$} & \multirow[b]{2}{*}{$p$ value } \\
\hline & $N$ & $\%$ & $N$ & $\%$ & \\
\hline $\begin{array}{l}\text { Prevalence of anxiolytic and/or antidepres- } \\
\text { sant consumption (before the crisis period: } \\
\text { 2008) }\end{array}$ & 67 & $10.6(8.2-13)$ & 127 & $12.4(10.4-14.5)$ & 0.269 \\
\hline $\begin{array}{l}\text { Prevalence of anxiolytic and/or antidepres- } \\
\text { sant consumption (at the time of interview: } \\
\text { 2015) }\end{array}$ & 95 & $15.1(12.2-18)$ & 138 & $13.5(11.4-15.6)$ & 0.375 \\
\hline Period: 2008 & 630 & 38.2 & 1021 & 61.8 & \\
\hline \multirow[t]{2}{*}{ Period: 2015} & 630 & 38.2 & 1021 & 61.8 & \\
\hline & Mean & S.D & Mean & S.D & $p$ value \\
\hline Age: 2008 & 41.3 & 10.1 & 40.2 & 10.1 & 0.039 \\
\hline Age: 2015 & 48.3 & 10.1 & 47.2 & 10.1 & 0.039 \\
\hline Family SES: 10 years previously & 6.3 & 1.5 & 6.1 & 1.8 & 0.012 \\
\hline Family SES: 2015 & 5.6 & 1.8 & 5.3 & 2.1 & 0.006 \\
\hline Variables at the individual level & $N$ & $\%$ & $N$ & $\%$ & $p$ value \\
\hline Men & 297 & 47.1 & 520 & 50.9 & 0.135 \\
\hline Women & 333 & 52.9 & 501 & 49.1 & \\
\hline Illiterate, no diploma & 111 & 17.6 & 203 & 19.9 & 0.000 \\
\hline Primary education & 262 & 41.6 & 459 & 45.0 & \\
\hline Secondary education & 154 & 24.4 & 267 & 26.2 & \\
\hline Higher education & 103 & 16.3 & 92 & 9.0 & \\
\hline $\begin{array}{l}\text { Crisis impact on family SES (Mean and } \\
\text { S.D.) }\end{array}$ & -0.1 & 0.9 & 0.0 & 1.0 & 0.074 \\
\hline $\begin{array}{l}\text { Characteristics of census tracts included in } \\
\text { the study }(2001)^{b}\end{array}$ & Mean & S.D & Mean & S.D & $p$ value \\
\hline$\%$ of population with low education level & 23.08 & 17.66 & 28.23 & 11.61 & 0.136 \\
\hline$\%$ of population in dwellings without a toilet & 2.96 & 2.94 & 8.67 & 17.63 & 0.089 \\
\hline$\%$ of population unemployed & 28.95 & 8.13 & 31.48 & 8.98 & 0.226 \\
\hline
\end{tabular}

${ }^{\text {a } F o r ~ c a t e g o r i c a l ~ v a r i a b l e s, ~ t h e ~} p$ value is obtained from Pearson Chi-square test comparing proportions between control and target areas

b2001 Atlas of Urban Vulnerability in Spain

\section{Discussion}

We investigated whether the use of anxiolytics and/or antidepressant changes during a period of economic crisis, following the implementation of two area-based programmes in deprived urban areas following the pre-crisis period. Overall, we did not observe a positive change in the use of psychotropic drug consumption in the target areas. However, our findings support the hypothesis that area-based initiatives seem to moderate the negative consequences of the economic crisis on mental health risks, measured by the consumption of psychotropic drugs. Compared with the deprived control areas, residents in the target areas tended to show a less increase in their use of psychotropic after the economic crisis. 


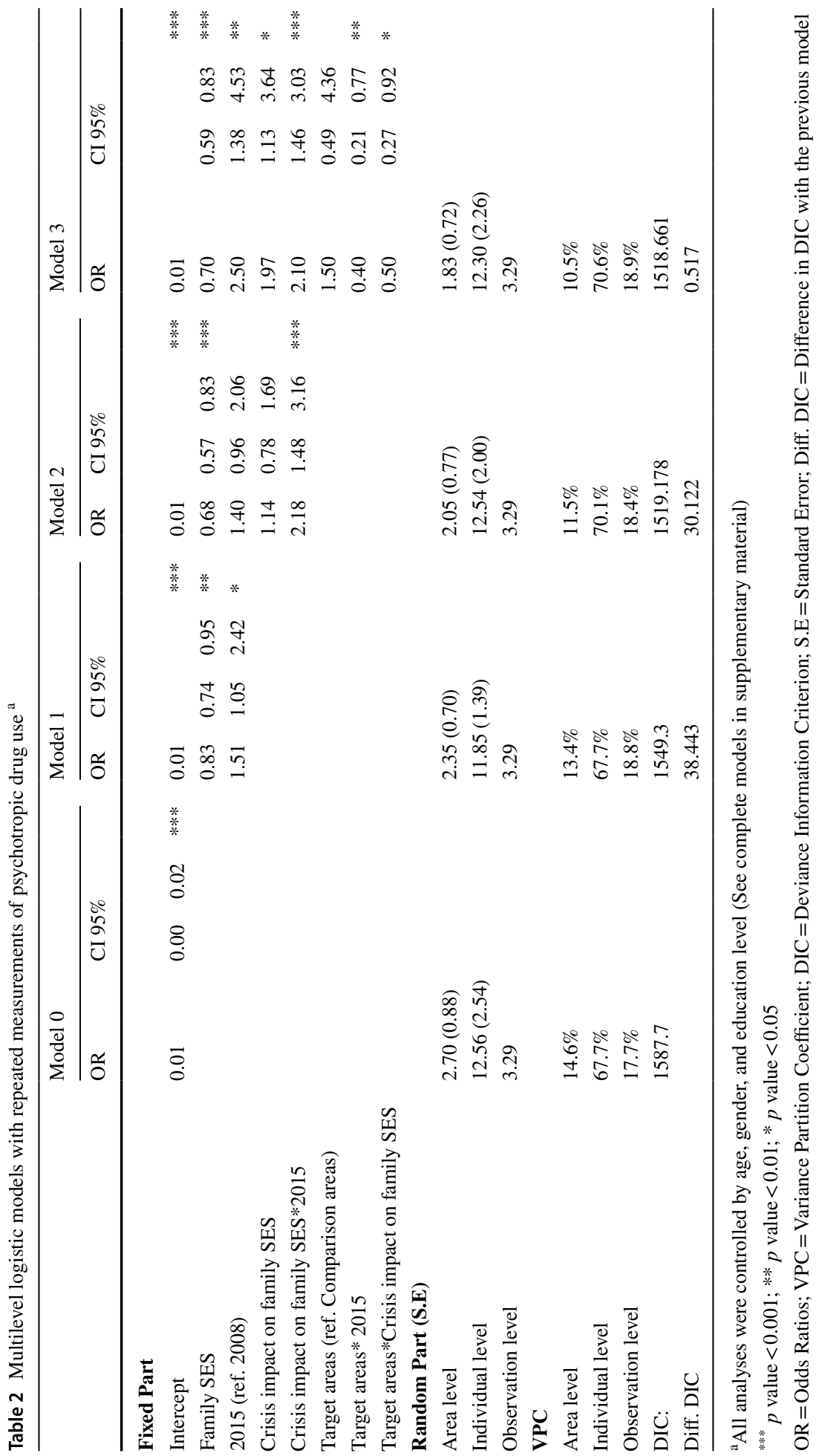


2008

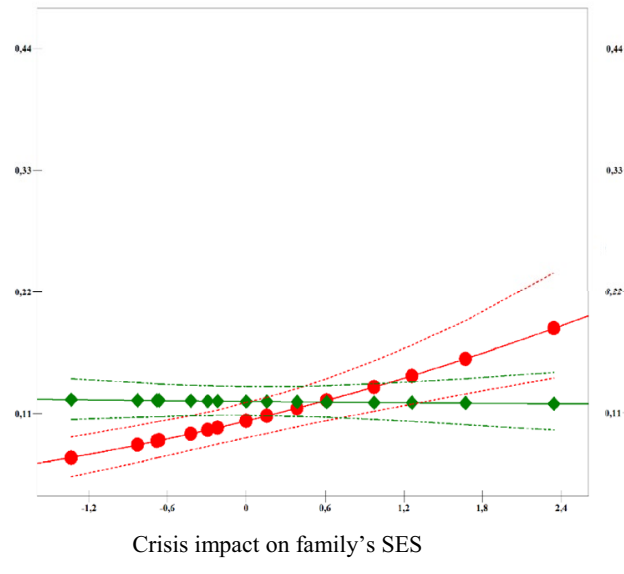

$\leadsto$ Target areas
2015

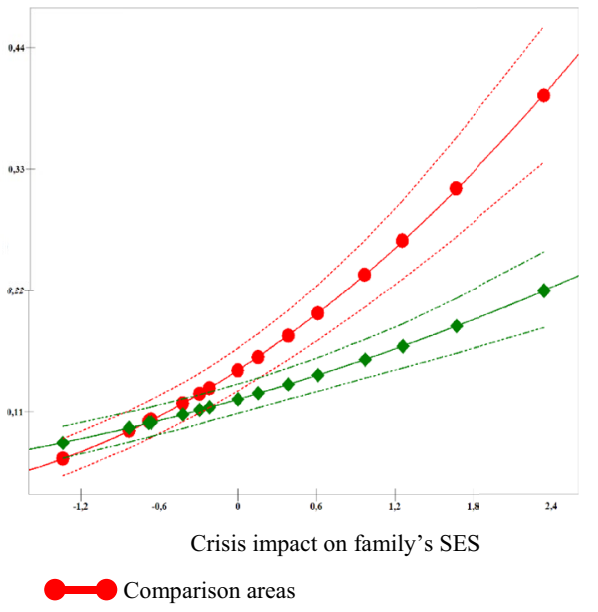

Dash lines: $95 \%$ CI

Fig. 2 Predictions for anxiolytic and/or antidepressant use considering the impact of economic crisis for residents in target and comparison areas

This is particularly evident if we compare people with greater exposure to the negative consequences of the economic crisis on their family' SES living in target and control areas (see Fig. 2).

As far as we know, this study is the first to consider economic turmoil as part of a 'natural experiment' to test whether urban policies in vulnerable areas might act as moderators of the risk of mental health disorders, particularly when people are subject to the loss of individual resources (families' downward social mobility). Some limitations of the present study should be acknowledged: First, the post-intervention design compels us to carry out retrospective measurements on some of our main variables of interest. As we have explained in the methods section, according our external validation, recall bias seem not be operating in our dependent variable. Moreover, we have also tested that retrospective questioning did not affect the difference between target and control areas. The second limitation is that our analysis has not been broken down into more specific mechanisms regarding the ways in which an intervention modifies resources and/or which of them are affected. In this regard, it would be necessary to have access to more information about different processes at the community level pre and post-interventions.

Our results are in line with a growing body of knowledge suggesting that area-based interventions, particularly urban regeneration programmes, can lead to promoting resident's resilience to mental health risks. For example, some researchers have documented the benefits of housing improvements on mental health and (Thomson et al. 2003), and others have found significant improvements in the mental health and self-reported psychosocial status of the population who benefit from interventions (Kearns et al. 2011; Ludwig et al. 2008; Kelaher et al. 2010). Moreover, natural experiments show that area-based interventions in severely deprived neighbourhoods were associated with improvements in resident's mental health (White et al. 2017). This is particularly the case when interventions are more intensive (Jongeneel-Grimen et al. 2016), which is the case of the interventions in most of our target areas. Our results are also congruent with a quasi-experimental study 
on the assessment of the urban regeneration projects in Catalonia, documenting that mental health remained stable in target neighbourhoods and worsened for men in the comparison neighbourhoods after 2008 in Spain (Mehdipanah et al. 2014).

Recent research suggests that interventions focusing on places may be more effective in obtaining positive impacts on general health than interventions focusing on people (Droomers et al. 2016). The interventions analysed in our study entail processes oriented towards improving individual resources and skills (training courses, financial aid, housing improvements, etc.), and others focusing on place, which aim to improve 'collective resources' (infrastructure, services, equipment, transport, citizen participation, etc.). A previous study has also documented a larger reduction of inequality in preventable mortality in those target areas where interventions on individuals and places were combined, given as result more comprehensive intervention processes (Zapata Moya and Navarro Yáñez 2017). In this line, Interventions focused on collective resources linked to places could be interpreted like 'interventions which minimize the importance of individual resources' for health (Phelan et al., 2014), and accordingly would facilitate the distribution of health benefits for residents in target areas. Accordingly, our findings could be cautiously interpreted as indicating the moderating effect of interventions on the negative impact of economic crisis on mental health risk, especially in situations in which people suffered a sharp decline in their family 'flexible resources'. This is in line with the environment stress hypothesis, implying that the quality of residential area has an impact on mental health and how policies aiming to get improvements of environment in deprived urban areas can positively influence mental health of those who continued to live in the same area (Dalgard and Tambs 1997). Therefore, the two area-based programs appear to address health inequalities at a preventative level (e.g. wider environmental level) and also to mitigate harm at an individual level, but it would be beyond their scope, however, to undo the fundamental causes of health inequality as described by Phelan et al. (2010).

Area-based initiatives, combining individual and contextual interventions, might be well suited to complement general policies. In this sense, initiatives should integrate explicit actions to avoid the accumulation of disadvantages through people's life course and should consider the social and cultural particularities that might lead to the concentration of several risk factors for health in vulnerable urban areas. Unfortunately, area-based interventions analysed here were not designed with the explicit purpose of improving health and reducing health inequity, and therefore their design lacks a theoretical rationale for actions along those lines. We believe that to achieve significant transformations of health inequality in urban contexts, it would be necessary for policies to include a more elaborated insight into places as relational spaces, that is, as relevant social contexts for people's daily life (Abel and Frohlich 2012). For example, their design should consider more seriously the principle of 'agency structural transformation', that is, actions oriented not only towards providing neighbourhoods with the means or primary resources to improve residents' quality of life, but also towards intensifying actions that seek to improve residents' capabilities. Combining the provision and improvement of access to resources such as housing, physical environment enhancement, public services, etc., with actions intending to improve perceptions and capabilities to influence what people can effectively do with these resources (Frohlich et al. 2001). 


\section{Conclusion}

This study examined the relationship between area regeneration policies, the loss of socioeconomic resources of families living in vulnerable neighbourhoods in Andalusia (Spain) as a result of the 2008 crisis and the consumption of anxiolytics and/or antidepressants as a proxy indicator for mental health disorders. The results indicate that place-based policies, including housing, built environment interventions and social integration initiatives moderated the consumption of anxiolytics and/or antidepressants, especially among those who see their socio-economic position worsening relatively after the economic crisis. This suggests that place-based policies could act as a buffer against negative health consequences in the face of sudden loss of socio-economic position. This result is indicative of a line of work to be further explored, as this would allow progress in the studies of health inequalities as to how comprehensive context-focused interventions can interact with social mobility processes and impact on the health of the population. More empirical research would be needed in order to determine to what extent this can also be observed in other health outcomes and to analyse which specific elements of area-based policies would achieve the greatest positive impact on the health of the vulnerable population.

In terms of public policy research, this paper offers new perspectives on the debate between place-based and people-based policies. Urban regeneration policies are an example of placebased policies aimed at improving the quality of life through integrated interventions that combine the provision of individual and collective resources in different policy areas. Since the 1990s, this strategy has been the incorporation of urban policies in the European Union (European Commission 2015); place-based policies are a basic orientation of the European Union's cohesion policy (Mendez 2013), and are a key aspect of the guidelines of the New Urban Agenda promoted by the United Nations within the framework of the Sustainable Development Goals (UN, 2017). Comparing the experimental and control areas, the main results support the idea that place-based policy could be more effective than sectoral policies in overcoming social problems in vulnerable neighbourhoods, or at least in preventing the effect of disruptive factors on such as the 2010 economic crisis. The EU is currently introducing several changes to the Cohesion Policy to address the crisis caused by the COVID-19 pandemic. This article shows that comprehensive area-based policies, a cornerstone of EU urban policies, could be well suited to modulate the potential effects of this current crisis.

Funding This research is part of RUCOSA project (Urban Regeneration and Social Cohesion in Andalusia: towards an evaluative analysis) which has been funded by the I+D framework of the Department of Housing-Government of Andalusia and the ERDF-European Union. The authors thank the staff and researchers at the Consejería de Fomento y Vivienda of the Junta de Andalucía, and of all its agencies for their work and professionalism in supporting the development of this project. This work has also been supported by the Jean Monnet Chair in European Urban Policies (EUrPol), Erasmus + programme of the European Union (Ref. Project: 612051-EPP-1-2019-1-ES-EPPJMO-CHAIR). The European Commission's support for the production of this publication does not constitute an endorsement of the contents, which reflect the views only of the authors, and the Commission cannot be held responsible for any use which may be made of the information contained therein.

\section{Compliance with ethical standards}

Conflict of interest Angel R. Zapata Moya and Clemente J. Navarro Yáñez declare that they have no conflict of interest.

Informed consent Informed consent was obtained from all individual participants included in the study. 


\section{References}

Abel, T., \& Frohlich, K. L. (2012). Capitals and capabilities: linking structure and agency to reduce health inequalities. Social Science \& Medicine, 74(2), 236-244.

Baba, C., Kearns, A., McIntosh, E., Tannahill, C., \& Lewsey, J. (2017). Is empowerment a route to improving mental health and wellbeing in an urban regeneration (UR) context? Urban Studies, 54(7), 1619-1637.

Baba, C. R. E., McIntosh, E., Tannahill, C., Lewsey, J., \& Kearns, A. (2014). Empowerment as an alternative pathway to health gains in urban regeneration; findings from the GOWELL study: Camilla Baba. European Journal of Public Health, 24(21), 64-081.

Barceló, M. A., Coll-Negre, M., Coll-de-Tuero, G., \& Saez, M. (2016). Effects of the Financial Crisis on Psychotropic Drug Consumption in a Cohort from a Semi-Urban Region in Catalonia, Spain. PLoS ONE, 11(2), e0148594.

Boudreau, D. M., Daling, J. R., Malone, K. E., Gardner, J. S., Blough, D. K., \& Heckbert, S. R. (2004). A validation study of patient interview data and pharmacy records for antihypertensive, statin, and antidepressant medication use among older women. American Journal of Epidemiology, 159(3), 308-317.

Cagney, K. A., Browning, C. R., Iveniuk, J., \& English, N. (2014). The onset of depression during the great recession: foreclosure and older adult mental health. American Journal of Public Health, 104(3), 498-505.

Clark, C., Myron, R., Stansfeld, S., \& Candy, B. (2007). A systematic review of the evidence on the effect of the built and physical environment on mental health. Journal of Public Mental Health, 6(2), 14-27.

Cotterchio, M., Kreiger, N., Darlington, G., \& Steingart, A. (1999). Comparison of self-reported and physician-reported antidepressant medication use. Annals of Epidemiology, 9(5), 283-289.

Cotterchio, M., Kreiger, N., Darlington, G., \& Steingart, A. (2000). Antidepressant medication use and breast cancer risk. American Journal of Epidemiology, 151(10), 951-957.

Dalgard, O., \& Tambs, K. (1997). Urban environment and mental health: a longitudinal study. The British Journal of Psychiatry: The Journal of Mental Science, 171, 530-536.

Diez Roux, A. V., \& Mair, C. (2010). Neighborhoods and health. Annals of the New York Academy of Sciences, 1186(1), 125-145. https://doi.org/10.1177/0739456X04267728.

Driessen, G., Gunther, N., \& Van Os, J. (1998). Shared social environment and psychiatric disorder: a multilevel analysis of individual and ecological effects. Social Psychiatry and Psychiatric Epidemiology, 33(12), 606-612.

Droomers, M., Jongeneel-Grimen, B., Bruggink, J. W., Kunst, A., \& Stronks, K. (2016). Is it better to invest in place or people to maximize population health? Evaluation of the general health impact of urban regeneration in Dutch deprived neighbourhoods. Health \& place, 41, 50-57. https://doi.org/10.1016/j. healthplace.2016.07.003.

European Commission (2015) Guidance for member states on integrated sustainable urban development. Available at https://ec.europa.eu/regional_policy/sources/docgener/informat/2014/guidance_sustainabl e_urban_development_en.pdf.

Evans, G. W. (2003). The built environment and mental health. Journal of Urban Health, 80(4), 536-555.

Fone, D. L., \& Dunstan, F. (2006). Mental health, places and people: a multilevel analysis of economic inactivity and social deprivation. Health \& Place, 12(3), 332-344.

Frohlich, K. L., Corin, E., \& Potvin, L. (2001). A theoretical proposal for the relationship between context and disease. Sociology of Health \& Illness, 23(6), 776-797.

Jongeneel-Grimen, B., Droomers, M., Kramer, D., et al. (2016). Impact of a Dutch urban regeneration programme on mental health trends: a quasi-experimental study. Journal of Epidemiology and Community Health. https://doi.org/10.1136/jech-2015-207016.

Kawachi, I., \& Berkman, L. F. (2014). Social capital, social cohesion, and health. In L. F. Berkman, I. Kawachi, \& M. Maria Glymour (Eds.), Social Epidemiology (2nd ed., pp. 290-320). Oxford, United Kingdom: Oxford University Press.

Kearns, A., Whitley, E., Mason, P., Petticrew, M., \& Hoy, C. (2011). Material and meaningful homes: mental health impacts and psychosocial benefits of rehousing to new dwellings. International Journal of Public Health, 56(6), 597-607.

Kelaher, M., Warr, D. J., \& Tacticos, T. (2010). Evaluating health impacts: Results from the neighbourhood renewal strategy in Victoria, Australia. Health \& Place, 16(5), 861-867.

Ludwig, J., Liebman, J. B., Kling, J. R., et al. (2008). What can we learn about neighborhood effects from the Moving to Opportunity experiment. American Journal of Sociology, 114(1), 144-188.

Malard, L., Chastang, J. F., \& Niedhammer, I. (2017). Changes in behaviors and indicators of mental health between 2006 and 2010 in the French working population. Revue d'epidemiologie et de Sante Publique, 65(4), 309-320. 
Martin-Carrasco, M., Evans-Lacko, S., Dom, G., et al. (2016). EPA guidance on mental health and economic crises in Europe. European Archives of Psychiatry and Clinical Neuroscience, 266(2), 89-124.

Mehdipanah, R., Marra, G., Melis, G., \& Gelormino, E. (2018). Urban renewal, gentrification and health equity: a realist perspective. European Journal of Public Health. https://doi.org/10.1093/eurpub/ckx20 2.

Mehdipanah, R., Rodríguez-Sanz, M., Malmusi, D., et al. (2014). The effects of an urban renewal project on health and health inequalities: a quasi-experimental study in Barcelona. Journal of Epidemiology and Community Health, 68, 811-817.

Mendez, C. (2013). The post-2013 reform of EU cohesion policy and the place-based narrative. Journal of European Public Policy, 20(5), 639-659. https://doi.org/10.1080/13501763.2012.736733.

Ministerio de Fomento (2015) Atlas de vulnerabilidad urbana en España 2001 y 2011: Metodología, Contenido y Créditos. Gobierno de España. https://www.fomento.es/NR/rdonlyres/8E15B 071-12B5-4390-A913-E7349266E9FA/111284/20120125_METODOLOGIA_ATLAS.pdf. Accessed 13 December 2017

Northridge, M. E., \& Freeman, L. (2011). Urban planning and health equity. Journal of Urban Health, $88(3), 582-597$.

Northridge, M. E., Sclar, E. D., \& Biswas, P. (2003). Sorting out the connections between the built environment and health: a conceptual framework for navigating pathways and planning healthy cities. Journal of Urban Health, 80(4), 556-568.

Phelan, J. C., Link, B. G., \& Tehranifar, P. (2010). Social conditions as fundamental causes of health inequalities theory, evidence, and policy implications. Journal of Health and Social Behavior, 51(1 suppl), S28-S40:37.

Posternak, M. A., Young, D., Sheeran, T., Chelminski, I., Franklin, C. L., \& Zimmerman, M. (2004). Assessing past treatment history: test-retest reliability of the treatment response to antidepressant questionnaire. The Journal of Nervous and Mental Disease, 192(2), 95-102.

Posternak, M. A., \& Zimmerman, M. (2003). How accurate are patients in reporting their antidepressant treatment history? Journal of Affective Disorders, 75(2), 115-124.

Ross, C. E. (2000). Neighborhood disadvantage and adult depression. Journal of Health and Social Behavior, 41(2), 177-187.

Silva, M., Antunes, A., Frasquilho, D., Cardoso, G., \& Caldas-de-Almeida, J. M. (2017). The impact of the economic crisis on the use of psychotropic medication in Portugal: Preliminary results of the national mental health survey follow-up. European Psychiatry, 41, S579.

Silver, E., Mulvey, E. P., \& Swanson, J. W. (2002). Neighborhood structural characteristics and mental disorder: Faris and Dunham revisited. Social Science \& Medicine, 55(8), 1457-1470.

Spencer, J. H. (2005). How to think about place and people approaches to poverty the significance of the earned income tax credit as neighborhood investment. Journal of Planning Education and Research, 24, 292-303.

Stegmueller, D. (2013). How many countries for multilevel modeling? A comparison of frequentist and Bayesian approaches. American Journal of Political Science, 57(3), 748-761.

Thomson, H., Atkinson, R., Petticrew, M., \& Kearns, A. (2006). Do urban regeneration programmes improve public health and reduce health inequalities? A synthesis of the evidence from UK policy and practice (1980-2004). Journal of Epidemiology and Community Health, 60(2), 108-115.

Thomson, H., Petticrew, M., \& Douglas, M. (2003). Health impact assessment of housing improvements: incorporating research evidence. Journal of Epidemiology \& Community Health, 57(1), 11-16.

UN-Habitat (2017): The New Urban Agenda, United Nations, https://habitat3.org/the-new-urban-agenda/

Weich, S., Blanchard, M., Prince, M., Burton, E., Erens, B. O. B., \& Sproston, K. (2002). Mental health and the built environment: cross-sectional survey of individual and contextual risk factors for depression. The British Journal of Psychiatry, 180(5), 428-433.

White, J., Greene, G., Farewell, D., et al. (2017). Improving mental health through the regeneration of deprived neighborhoods: a natural experiment. American Journal of Epidemiology. https://doi. org/10.1093/aje/kwx086.

Zapata Moya, A. R., \& Navarro Yáñez, C. J. (2017). Impact of area regeneration policies: performing integral interventions, changing opportunity structures and reducing health inequalities. Journal Epidemiology and Community Health, 71, 239-247.

Publisher's Note Springer Nature remains neutral with regard to jurisdictional claims in published maps and institutional affiliations. 